Research Article

Journal of Research and Review in Science, 153-159

Volume 5, December 2018

DOI:10.36108/jrrslasu/8102/50(0122)

ORIGINAL RESEARCH

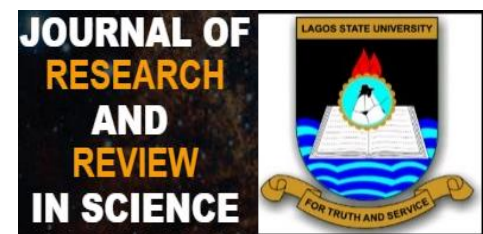

\title{
Parasitism and the Menace of Open defeacation in Nigeria (A Review)
}

Okwa O. Omolade ${ }^{1}$, Mordi E. Chukwudumebi² and Adefowope A. Esther ${ }^{3}$

${ }^{1}$ Department of Zoology,

Faculty of Science,

Lagos State University, Ojo

\section{${ }^{*}$ Correspondence}

Okwa O. Omolade,

Department of Zoology,

Faculty of Science,

Lagos State University, Nigeria.

Email:okwaomolade@hotmail.com

\begin{abstract}
:
Introduction: Parasitism is a biological interaction between two organisms of different species, the smaller one known as the parasite is metabolically dependent on the bigger one called the host. The parasite inflicts injury and may ultimately kill the host. Open defeacation (OD) is the human practice of emptying the bowels in an open space rather than a properly designed structure built purposely for handling human waste. $O D$ is caused mainly by poverty, cultural misconceptions and lack of suitable toilets and the effect such as parasitism kills about 1.8 million people yearly, many of which are children. Nigeria is the third on the list of the top six countries in the world where OD is practiced with a rate of $27 \%$. OD leads to contamination of soil, water bodies and vegetation with infectious cyst and oocyst stages of intestinal protozoa parasites, eggs of soil transmitted nematodes and larvae stages of various helminthes.
\end{abstract}

Aims: Drinking water and aquatic environment are polluted by OD and this impact on human health and aquatic life. Educating the populace on personal hygiene, proper wastes disposal and the health implications of $\mathrm{OD}$ and other associated problems are essential if Nigeria plans to eradicate OD to a zero threshold.

Results: Provision of safe water and working public toilets in rural and urban areas are strongly recommended. Enforcement of sanitation laws and proper disposal of human waste is advocated.

Conclusion: We conclude that Nigerians must awake and enhance a culture of sanitation and hygiene to bring these diseases of poverty to a drastic reduction

Keywords: Open defeacation, Parasitism, Nigeria, Contamination, Soil transmitted nematodes.

\section{INTRODUCTION}

Open defeacation (OD) is the human practice of defeacating indiscriminately, which is emptying of bowels in an open space rather than using an enclosed properly designed structure built specially for handling human waste such as toilets or latrines. Such open spaces include soils, fields, bushes, forests, ditches, gutters, canals, abandoned or uncompleted buildings, drainages and water bodies. People go out to defeacate in these places rather than using the toilets or latrines. WHO/UNICEF described this act as uncivilized, barbaric and a hall mark of under- development [1]. OD 
includes unhygienic and improper disposal of human waste in public places such as bushes, drainages, refuse dumps, cellophane bags, uncompleted buildings and the soil. OD is practiced not only in the rural areas but also in some urban areas especially in slums where many houses are built without toilets. About 892 million people or $12 \%$ globally practice OD especially in underdeveloped and developing countries in sub-Saharan Africa and Asia [1]. Lack of suitable toilets and sanitation kills about 1.8 million people a year of which many are children [2]. Lack of basic sanitation and indiscriminate $O D$ is the world's biggest cause of infection [3].

Parasites associated with $O D$ are usually intestinal parasites whose stages as cyst, oocyst, eggs or larvae gets into the environment when infected persons defecate in the open. These stages get to humans through the feacal - oral route. Intestinal parasites show a correlation with regions having no toilets and where OD is practiced [4].

Objectives: This review intends to sensitize the populace on the myriad of health implications and hazards of $\mathrm{OD}$ and the need for a cleaner environment. There is a need to reinforce and engage the interest of concerned authorities like political and health authorities to intensify more efforts in eradicating the menace of OD to a zero threshold.

\subsection{Global view of open defeacation}

WHO / UNICEF, reported that 2.6 billion people worldwide have no toilets, while $10 \%$ defeacate out of doors [1]. In 2001, the World Toilet Organization (WTO) declared November 19th as the World Toilet Day to raise global awareness of the struggle against $O D$. It is obvious from table 1 below that OD is practiced mostly in developing and under-developed countries. Developing countries have less developed industrybased index and low Human development index (HDI) relative to developed ones. Under developed countries are characterized by chronic mass poverty, low incomes and very low HDI relative to developing others [5]. No wonder these parasitic infections have been called diseases of poverty and neglected tropical diseases. In developed countries, outbreaks of parasitic infections have been eradicated where citizens have access to sanitation and clean water [6].

Globally, India is the top country in OD rate. WHO / UNICEF states that, 521 million people in Indian alone are involved in OD and this is nearly half the country's population [1]. India accounts for $59 \%$ of 1.1 billion people who practice OD causing serious negative effect on humans and animals. However, India has set a target of 2019 for eradicating OD and adopting a system call "Swatch Bharat" mission (Clean India initiative) to generate awareness and share information of the need for change and to embrace a culture of personal hygiene and basic sanitation. The supreme court of India had declared that sanitation is a fundamental human right [7].
Table 1: Top six countries of the world where open defeacation is common

\begin{tabular}{|l|l|l|l|l|}
\hline $\begin{array}{c}\mathrm{S} \\
\mathrm{N}\end{array}$ & Country & $\begin{array}{c}\text { OD } \\
\text { rate } \\
(\%)\end{array}$ & $\begin{array}{c}\text { Est. Pop } \\
\text { with } \\
\text { No toilets }\end{array}$ & \multicolumn{1}{|c|}{ Status } \\
\hline 1 & India & 40 & 818 million & Developing \\
\hline 2 & China & 30 & 607 million & Developing \\
\hline 3 & Nigeria & 27 & 108 million & Developing \\
\hline 4. & Ethiopia & 26 & 100 million & Under-developed \\
\hline 5. & Indonesia & 12 & 109 million & Developing \\
\hline 6. & Pakistan & 12 & 98 million & Developing \\
\hline
\end{tabular}

Sources: WHO/ UNICEF (2017), World Toilet Day (2017)

\subsection{Reasons for open defeacation}

- Poverty and overcrowding: Poverty is a bane of lack of housing and houses without toilet facilities. OD is common when sanitation infrastructures are not available, inadequate or poor. Even, students in some academic hostels resort to use of personal potties or buckets instead of using toilets [8]. This is also the norm in overcrowded houses where toilets are inadequate.

- Fear of public toilets: Where there are unhygienic toilets, people do not want to use unflushed or filthy toilets for fear of contacting diseases, so they rather go for OD. In actual fact, infectious diseases can be contacted from public toilets, door knobs and even tap handles.

- Cultural beliefs: There are still cultures that prohibit the sharing of toilets. For instance, in some African cultures it is forbidden for a man to share toilets with the daughter in- law. In India, where they have caste system, people regard sharing public toilets with a lower caste as a taboo. In some households with toilets, $40 \%$ still prefer to defeacate openly [7]

- Emergency situations: This happens with such individuals having dysentery and diarheoa and when undergoing a long journey away from home or conveniences.

- Nomadic and itinerant life: People who move from place to place like the nomadic herdsmen and homeless vagabonds often defeacate in the open.

\subsection{Dangers of open defeacation}

- Effect on the environment: The effect of lack of access to sanitation has a macro-economic impact on the environment. To say that OD wreaks havoc on the environment and society is an understatement.

a. Human waste is toxic and contains about 10 million viruses, I million bacteria and of course over a thousand parasites stages $[9,10]$

b. Harmful microbes and toxins which do not decompose easily in the soil have negative effects which may not be handled easily.

c. About $90 \%$ of pharmaceutics (drugs and antibiotics) taken by people are excreted by 
urination into the environment. Plants, aquatic ecosystems and animals are part of our environment and they get their own share of these pathogens and drug residues. These pathogens and toxins eventually get back to humans [11]

d. The built of filth due to improper excreta disposal and pollution of aquatic ecosystem becomes inevitable with the consequent negative effects on aquatic life.

- Danger: This include the risk of being bitten by snakes or other nocturnal wild animals which may be encountered in the night when most open defecators operate [2]

- Sexual assault and rape: Female need security and privacy so they need to walk far away to a suitable place and are exposed to sexual assault and rape during OD acts [ 2]

\subsection{Open defeacation in Nigeria}

Nigeria is third on the list of the top six countries in the world where OD is practiced. The old culture of OD has held sway in many parts of the country in spite of the rapid urbanization. WHO/UNICEF [1], reported that 771 local government areas in Nigeria practice OD and 47 million Nigerians defeacate openly. This implies that $1 / 3$ of the nation practice OD. To cry out loud, this infamous act is in fact increasing at an alarming rate in Nigeria even in urban areas. Many Nigerians live in deplorable conditions, some wait till nightfall to defecate, some defecate inside their house and get rid of it by night by the "short put" method (Throwing waste forcefully over on bushes or refuse dumps). Human excrement has become a common site on rail tracks, bushes, fields and dump sites even in urban area. In rural areas, bushes facilitate OD [12]. The menace of OD in Nigeria is appalling, despite huge technological, scientific and industrial advancements [13].

Poverty still remains a significant at $33.1 \%$ in Nigeria in spite of the high economic growth rate averaging $7.4 \%$ in the country [14]. A top UNICEF official exclaimed in 2017 that: "Why must a heavy weight country like Nigeria, held in high regard globally be entangled with such deplorable infamy? [4]. This has casted blight on the nation as Africans' biggest economy and most populous country".

\subsection{Global status of common intestinal parasites associated with open defeacation}

Intestinal parasites are worldwide in distribution but have persisted in places where OD is practiced. They have disappeared where sanitation and human waste has improved [1]. Intestinal parasites are often underdiagnosed and underestimated in high risk areas. Soil transmitted nematodes (STNs) are especially common in remote rural communities with the poorest of the poor and the most deprived people who can hardly make a hue and cry about their plight of unsafe drinking water and poor sanitation.

World health organization (WHO) had reported that about 2 billion people (24\%) world-wide have STNs of which 866 million are in sub-Saharan Africa [15]. It was estimated that 1 billion people each have been infected with ascariasis and trichuriaisis globally [15]. A global estimate of STNs in 2010 was 438.9 million: with 819 million for Ascaris lumbricoides, 600 million for Ancylostoma duodenalis, 464.6 million for Trichuris trichiura and 30-100 million for Strongyloides stercoralis [16]. Taeniasis and Cysticercosis was reported as affecting 100 people worldwide [17]

\subsection{General life cycle of intestinal parasites associated with open defeacation in Nigeria}

Protozoa has life stages altering between proliferative stages. The cyst is a dormant and disseminating stage of protozoa with resistant tough shell which is the infective stage of intestinal sarcodina and mastigophorans. These groups of protozoa transit between active adult trophozoite to the dormant cyst which is resistant to environmental conditions but susceptible to desiccation [6]. About 45 million cysts may be passed out from one infective person with amoebiasis in a day [18]. The cyst of B .coli is yellowish or greenish with round, tough and heavy with two layers. G. lamblia has hard walled cyst with four nuclei and a disintegrating flagella [10]. The cysts are also the diagnostic stages of these parasites. The oocyst is an infectious resistant stage, which is spherical in shape with two layers and is transparent with a well-defined double outline. It usually sporulates in the soil and is the infectious and diagnostic stage of the group of parasitic protozoans called apicomplexans.

The cyst / oocyst can both survive harsh environment without access to nutrients, temperature, water or oxygen for a long period. This enables the cyst /oocyst to survive outside the body of a host and to be easily transmitted form one host to the other. For protozoan, cyst / oocyst devoid from the feaces of an infected person get to the environment by OD. This results into a new infection when the infectious cyst/oocyst is swallowed accidentally with contaminated food, vegetables, fruits or water.

STNs eggs are very resistant, viable for a long period and embryonate under the most adverse conditions. The eggs of $A$. lumbricoides are mammilated and have an ascariocide layer which is very resistant and can be viable in the soil for 10 years [19]. About 200,000 eggs can be deposited by a person suffering from ascariasis in a day [6]. The eggs of T. trichiura are lemon or barrel shaped with bipolar protuberances at the ends. Hookworms' eggs are transparent with blastomeres when they are excreted on the soil but embryonate to the infective filariform larvae stage called L3 hookworm is prevalent which can survive and develop even in damp soil with longetivity of up to three weeks. L3 eventually penetrates human skin. The larvae of $A$. duodenalis are also infectious if swallowed accidentally [10].

\section{How transmission of these parasites occur}

- Parasite stages (Cysst, oocysts, eggs and larvae), from human feaces contaminates, vegetables and fruits. If these stages are ingested from improperly 
washed vegetables and fruits, they may infect new individuals. Some of these vegetables and fruits could have been smeared with waste water or planted with untreated human or animal feaces.

- Parasite stages can be ingested from contaminated drinking water sources. In rural areas, people defecate in water bodies believing that water flushes away the waste. This ends in the main water source for cooking and drinking of others rural folks.

- Children play in soil which may be contaminated and put hands in their mouth without washing, because they have low level of awareness.

- Currency notes contaminated with stages of parasites can infect handlers [20].

- Hookworm is prevalent where people preferred certain places for OD and use no foot wears. Larvae in soil can penetrate the skin of farmers, miners and other people who handle soil

- Insects known as mechanical transmitters such as houseflies and cockroaches easily perch or crawl on feaces and spread parasite stages on open food, foodstuffs, fruits and vegetables.

- Oocyst of Cryptosporidium is most commonly obtained from unfiltered, untreated water from feacally contaminated sources. The infection can also be obtained from contamination of food and water with infected cattle or dog feaces.

- Cyclosporiaisis is mainly contacted from contaminated water sources, vegetables and sewage contamination. An outbreak of cyclosporiaisis was recorded in the United States, Europe and Canada from infected imported raspberries and straw berries [6]

- Open defeacators with taeniasis shed gravid proglottids with their feaces which contains eggs of tapeworm. This contaminates vegetation in which the animal intermediate hosts eventually graze on.

\subsection{Update on the survey of parasites associated with open defeacation in Nigeria}

Ogbolu et al reported that there has been increased incidence of food borne illness linked to contaminated common vegetables such as water leaf: Talinum triangulare) and 'soko': Celosia argentea in South western, Nigeria [21] . In his study, these vegetables were contaminated with several stages of intestinal parasites as Strongyloides stercoralis larvae at 49\%. B. coli is usually the rarest protozoa cyst (as also observed in the study) had a prevalence of $0.8 \%$. B. coli infection should however not be taken for granted because it could be fatal [10]. In a study in South Eastern, Nigeria, childhood malaria was confounded by intestinal parasites. In the study, $27 \%$ of the children with malaria had giardiasis and amoebiasis but the prevalence was lower in malaria free children [22].

In another study in Zaria, Kaduna State, B. coli co-existed with Cryptosporidium in infected individuals and the water and soil sampled in the area contained the cyst and oocyst of both parasites [23].

In Ogun State, cryptosporidiosis co-existed with amoebiasis, giardiasis and hookworm infections [24]. A prevalence of $2.3 \%$ and $2.9 \%$ for Cryptosporidiosis were observed in Ogun State and the Niger Delta respectively [24]. In a study in Rivers State, all the intestinal parasites co-existed in sympatry in the 13 local government areas studied and the infection rate was especially high for B. hominis and G. lamblia [25]. In a study in Edo State, a prevalence of $3.1 \%$ was obtained for Isospora belli infection among HIV patients with no regard for gender and age [26]. This coexistence of parasites (polyparasitism) has serious health consequences.

The STNs, A. lumbricoides and Trichuris trichiura had $76 \%$ and $74 \%$ prevalence respectively in Nigeria as at 1990 [27]. A prevalence of $83.3 \%$ for STNs in Era-Awori community in Lagos State, of which only $A$. lumbricoides had a prevalence of $67.7 \%$, was obtained in a study [28]. In another study in Ukwuani community in Delta State, a prevalence of $92.7 \%$ for STNs with A. lumbricoides again predominating at $76.8 \%$ [29] was obtained. WHO singled out Nigeria for special comment because 15 million Nigerians were estimated to harbour A. lumbrioides, the most prevalent STN in Nigeria [16]. Hookworm the "vampire of the gut" was predominant among school children in Edo State [30]. Taeniasis has been least investigated compared to other intestinal parasites, but in a study in Odeda, Ogun State, 41\% prevalence among school children was obtained [31]. Taeniasis was also highly prevalent among pupils in Niger State [32]. However, in all these surveys, children are the most vulnerable and prone to intestinal parasites associated with OD.

\section{MATERIAL AND METHODS}

\subsection{Prevention and control of parasites associated with open defeacation}

- Avoidance of OD and proper disposal of human feaces is very crucial as prevention is better than cure.

- Boiling and filtering water from ponds and wells meant for drinking is essential especially in rural areas with no pipe borne water.

- Personal hygiene, hand washing after visiting toilet, handling money and changing children diapers is crucial. Children's feaces are more likely to be handled carelessly but it contains more pathogens than that of adults [9].

- Parents and care givers who handle infected people should frequently wash their hands.

- People should avoid walking bare footed in hookworm and threadworm endemic areas.

- Educating children on hand washing and periodic deworming of children is important.

\section{RESULTS AND DISCUSSION}

3.1 Measures for the prevention of open defeacation in Nigeria

- Provision of pit latrines or bucket latrines in rural areas, slums, poor settings and in camps of 
refugees and internally displaced people (IDP) where water may be scarce

- Provision of mobile toilets and public toilets with water closets in designated urban areas. Such toilets should be maintained with water supply and proper flush system especially for homeless, nomadic and itinerant people

- Provision of safe water for drinking according to the goals of World Water Day (March, 22nd).

- Communities must be coerce to stop the act of OD by adopting methods and providing the needed infrastructure.

- Toilets should not be an afterthought so house owners with no toilets should be prosecuted and such houses sealed off.

- Health education to specific targeted population such as people in slums and impoverished areas on the importance of respecting the environment and emphasing the harmful effects of $O D$

- Civic education to people to debunk sanitation myths about sharing or using toilets is needed to break them away and adjust from such destructive cultural beliefs.

- Data on demography, living conditions of citizens is needed to guide policies in order to give support to the identified poverty stricken areas where $O D$ is the norm.

- Identified communities must be enlightened that OD is condemnable, terrible, destructive, animalistic and outdated.

- Enforcement of strict environmental sanitation laws against defaulters if the above measures have been implemented.

- Organizations like Lagos State Environmental Sanitation Corps (LAGESC), Water and Sanitation Hygiene Sector (WASH), Environmental Protection Agency (EPA) should not relent in their efforts to enforce strict environmental laws.

\section{CONCLUSION}

If Nigeria considers her most valuable asset to be her citizens then nothing should be considered too much to eliminate the menace of OD. It is a known fact that many under privileged Nigerians live below poverty level and deplorable conditions. What is the point of enforcing laws when provisions are inadequate and not available for the common people? Build a good toilet that works, then people will use it. A good toilet should be regularly cleaned, well ventilated, with water and free of disease agent.

Nigeria as the third among the top six countries in the world where OD is practiced is a negative image. Nigeria needs to borrow a leaf from India's laudable move. Nevertheless, the tip of the ice berg is that, if OD is curbed many diseases will be virtually eliminated. WHO/ UNICEF are of the opinion that access to sanitation and clean water should be a fundamental human right and not a privilege [1]. BMGF reiterated that water and sanitation are essential elements in curtailing the menace of $O D$ [2]. OD is a mark of poor governance and neglect of the poor citizens [4]. There should be a concerted effort to provide adequate and efficient toilets in public places so that people will have no excuse to defecate openly. All hands must be on deck to ensure that this barbaric act becomes history. Additional systems must be incorporated to prevent human waste from being released to the environment such a leakage of septic tanks and overflowing pit latrines and soak ways. According to Water AID [11], Nigeria will only be able to deliver a community source of clean water within a 30 minutes round trip by 2039 and this looks bleak to achieve. In spite of this, Nigeria needs a great sanitary re-awakening to curb the menace of OD.

\section{ACKNOWLEDGEMENTS}

The authors are grateful to Prof. GM Watkins and Chemistry Department, Rhodes University, Grahamstown, for providing facilities for this research.

\section{COMPETING INTERESTS}

We hereby declare that the authors have no competing interest

\section{AUTHORS' CONTRIBUTIONS}

This review was compiled and edited by the corresponding author: Dr. O.O Okwa. The literature search was carried out by Mordi Chukwudumebi and Adefowope Esther, the second and third authors. Both authors also wrote the first draft of the manuscript. The review was presented by the second author as a B.Sc seminar series of the Department of Zoology and Environmental biology and at the Faculty of Science, LASU international conference (FOSIC, 2018). All authors read and approved the final manuscript."

\section{REFERENCES}

1. WHO/ UNICEF: Progress on drinking water and sanitation. Joint monitoring programme for water supply and sanitation (JMP) 2017.

2. Bill and Melinda Gates Foundation (BMGF): Water, Sanitation and hygiene. Strategy overview global Development programme (SOGDP) 2011; 6pp.

3. UN-Habitat: The challenge of Slums - Global report on Human settlements .UN Human settlements programme. Earth scan publications Limited, London, UK 2003; 1 (6): 64-93

4. Nigerian-punch-news: www.punch.ng.com/open defeacation

5. World Bank Report: Environmental health and child survival: Epidemiology, Economic Experience. Washington D.C, 2008; 135pp 
6. Okwa OO: The Biology of the Tropical Parasites. Lambert Academic publishing, Germany 2016; 147pp.

ISBN: 978-3-330-00888-5.

7. Pandue HT: Environmental sanitation:

An ignored issue in Indian. Journal of Occupational and environmental

Medicine issue 12. 2008; 143pp

8. Adefowope AE: Toilet practices among students of Lagos State University and implications for disease transmission. B.Sc Project; Department of Zoology and Environmental Biology, Lagos State University, Nigeria, 2014; 77pp

9. Nigerian vanguard https://www.vanguard.ngr.com

news:

10. Oyerinde JPO: Essentials of Tropical Medical Parasitology: University of Lagos Press , Akoka. 1999; 435pp ISBN: 978-017-615-2

11. Water AID: Report of the United Nations international drinking water and sanitation decade. 2017

12. Nigerian guardian news: https://guardian.ng.feature

13. Ogundipe S: Report on the United Nations World Toilet Day, November 19, 2017

14.World Bank Report: www.who.int; www.ncbi.nlm.nih.gov. Washington D.C, 2014; $135 p p$.

15. WHO: Global burden of diseases: 2004-2008 Update. World Health Organization Geneva, 2008; 160pp ISBN: 9789241563710

16. WHO: developing guidelines for water, Sanitation and hygiene promotion in schools .http://who.int/linkfiles/SDE. World Health Organization Geneva, 2010; 60pp

17. Food and Agricultural Organization (FAO): Codes committee on food hygiene: Proposed draft guidelines for control of specific Zoonotic parasites in meat. Mimi, United States, 2013.

18. Stanley SL: Amoebiasis: Lancet 2003;361: 10251034

19. Dold C, Holland CV: Ascaris and Ascariasis. Microbes and infection 2011; 13(7) 632- 637

20. Okwa OO, Bello AS: Parasitic organisms on Nigerian naira notes in Ojo LGA, Lagos State, Nigeria. International Journal of Pure and Applied Zoology (United States) ISSN: 2320- 9585.2016; 2016;4(2) 221-224.
21. Ogbolu DO, Alli OA, Ogunleye VF, OlushogaOgbolu FT, Olaosun I: The prevalence of intestinal parasites in selected vegetables from open markets in South-western Nigeria. African Journal of Medicine and Medical Sciences 2009; 38(4) 319-324

22. Nwanguma BC, Alumanah EO: Concurrent giardiasis and amoebiasis infections in Nigerian Children diagnosed with Plasmodium falciparium: Prevalence and Pathophysiological implications Internet Journal of Tropical Medicine 2018; 6(1): 16. IS pub.com

23. Yatswako OO, Faleke ML, Guumbe ML and Daneyi A I: Cryptosporidium oocyst and Balantidium coli cyst in pigs reared semi-intensively in Zuru, Niger State, Nigeria. Pakistan Journal of Biological Science; 2007; 3435-3435 .Doi-10.3923/pjbs.

24. Reinthaler FF: Cryptosporidium in Ogun State, Nigeria. Tropical Medicine and Parasitology 1987; 38(1) 51-52

25. Abah A.E, Arene FOI: Status of intestinal parasitic infections among primary school children in Rivers State, Nigeria. Journal of Parasitological Research 2015; ID: 937096. 7 pp. http: dx doc.org/10.1155/2015-1937096

26. Akinbo FO, Okaka CE, Machado ID, Richardo: isospora belli in HIV/AIDS patients in Edo State, Nigeria.2009; Malaysian Journal of Medical Science 16(3)41-44

27. Holland CV, Asaolu SO: Ascariasis in Nigeria. Parasitology Today 1990; 6(5): 143-147 https://doi.org/10.10169-4758

28. Ibidapo CA and Okwa OO: The prevalence and intensity of soil transmitted helminthes in a rural community, Lagos Suburb, South western, Nigeria. International Journal of Agriculture and Biology 2008; 10: 89-92. http://www.fpublishers.org

29. Omar P, Ibidapo CA, Okwa OO: Prevalence and risk factors of geohelminthiasis in Umuebu community, Ukwani local government area, Delta state, southern Nigeria. British Journal of Medicine and Medical Sciences 2014; 4(5)1175-118

30. Tchunga KS, Nyenke CU Dunga KE , Anyamaobi OP , Ajugwuo A.O : Prevalence of hookworm in Elele and Okeh senior secondary school, Benin city, Edo State , Nigeria. Journal of Applied Microbiology and Biochemistry 2017; 1(4) 13-15. ISSN: 25761412: Doi. 10.21767/2576-472 10013

31.Mogaji HO, Adeniran AA, Fagbenro MT, Olabinke DB, Abe EM , Ekpo UF : Prevalence of Taeniasis in Odeda area of Ogun State, Nigeria. International Journal of Tropical Disease 2016;17(4): 1-8 ISSN: 2278-1005. Doi: 10.9734/jtdh/2016/27084 
32. Eke SS, Oguniyi T, Omalu ICJ, Otuu CA, Udeogu VO, Luka $\mathrm{J}$ et al.: Taeniasis among schoolchildren in some selected LGA of Minna, Niger State Nigeria. International Journal of Applied Biology Research 2014; 6(2) 80-86

33. Saeed AAH, Mahmoud AAK, Saed HA. Electronic spectrophotometric study on the molecular structure of some hydroxy Schiff bases. Canadian Journal of Spectroscopy. 1988: 33(4): 89-93.
34. Wanger A, Disk diffusion test and gradient methodologies. In: Schwalbe R, Steele-Moore L, Goodwin A. editors: Antimicrobial testing protocols. Boca Raton: Taylor \& Francis Group; 2007.

35. Sobola AO, Watkins GM, Van Brecht B. Synthesis, characterization and antimicrobial activity of copper (II) complexes of some ortho-substituted aniline Schiff bases; crystal structure of bis (2-methoxy-6imino) methylphenol copper (II) complex. South African Journal of Chemistry, 2014: 67: 45 - 51. 